\title{
DEVELOPING A MATLAB CODE FOR DETERMINE GEOMETRY OF ROCK MASS BLOCKS AND ITS APPLICATIONS IN MINING AND ROCK MECHANIC ENGINEERING
}

\author{
R. Yarahmadi*1 ${ }^{1}$, R. Bagherpour ${ }^{1}$, A. Khademian ${ }^{1}$, H. Mirzaie ${ }^{2}$, R. Kakaie ${ }^{2}$ \\ ${ }^{1}$ Isfahan University of Technology, Department of Mining Engineering, Isfahan, Iran \\ ${ }^{2}$ Shahrood University, Department of Mining Engineering, Petroleum and Geophysics, \\ Shahrood, Iran
}

(Received: June 14, 2015; Accepted: November 3, 2015)

\begin{abstract}
Various geological processes such as tectonic activities develop fractures and discontinuities in the rock mass body; these, in turn, form blocks with different shapes and sizes in the rock mass body. Accurate understanding of these blocks' geometry is essential in different domains of rock and mine engineering such as determination of yield in quarries, optimization of fragmentation energy, the design of blasting pattern, block stability in slopes and underground spaces and the prediction of dilution potential in caving methods exploitation. Because of costly operation and uncertainties in the measurement of fractures and discontinuities properties in $3 D, 2 D$ simple models are recommended. So far, all investigations have been focused on the problem of finding primary blocks analytically and mathematically, but these problem applications have been neglected slightly. This paper introduces a MATLAB code for geometry determination of rock mass blocks in two dimensional spaces and investigates the applications of it.
\end{abstract}

Key words: Rock mass geometry, Block size distribution, MatLab code, Quarry yield, Fragmentation, Blocks stability.

\section{Introduction}

Due to various geological processes such as tectonic activities, fractures and discontinuities are developed in the rock mass body; these discontinuities form blocks with different shapes and sizes in the rock mass body. A rock mass with its fracture system and blocks is shown in figure 1.

There are two general approaches for the determination of blocks geometry in rock mass in both two and three dimensional spaces. In the first approach, discontinuities are assumed to be infinite and parallel. Methods which are based on this approach determine the geometry of rock blocks through the geometrical parameter of rock mass such as joint spacing, RQD and so on.

The second approach is based on finite and real direction characteristics of discontinuities. Many researchers have developed different algorithms for the characterization of blocks in rock body.

Palmstrom et al. presented equations to determine rock mass blocks volume based on geometrical parameters of rock mass [1-3]. Warburton developed an algorithm and computer program to determine rock mass blocks geometry [4-5]. In this algorithm, joints are supposed to be parallel and infinite. Lu and Latham, Starzec and Tsang, Lin et al. and Smith also studied block-ability based on the first approach and geometrical parameters [6-9]. 


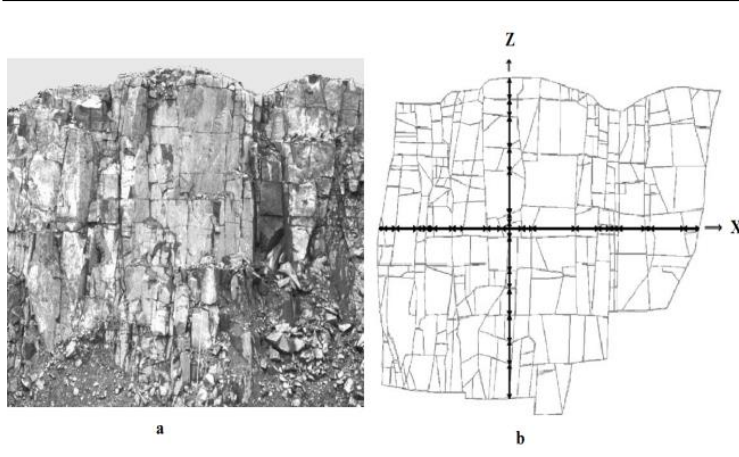

Figure 1. a) A fractured rock mass. b) $2 \mathrm{D}$ fractures system and blocks in this rock mass [10]

According to the second attitude, discontinuities are supposed to be real with limited length. In these methods, the main goal is determining blocks created by the contact of interface lines and planes. For the determination of blocks in 2 and 3 dimensions, various algorithms have been presented. Joaquim et al. claimed that graph theory based algorithms were the most optimum in terms of the essential time and the volume of data processing [11]. According to this algorithm, first, points of lines contact in 2 dimensions should be calculated and then a graph is generated using these points and lines, eventually creating several polygons as 2 dimensional blocks.

Heliot presented an algorithm based on the numerical methods in 3 dimensions for modeling discontinuities and specifying geometrical features of blocks [12]. Goodman and Shi offered an algorithm considering vector methods in 2 and 3 dimensions [13]. Shi also paid attention to detecting blocks formed through Curved and straight discontinuities contact in 2 dimensions [14]. SIMBLOCK software has been designed by Maerz and Germain for defining blocks in underground spaces [15]. Jing and Stephenson played the main role in the development of these algorithms according to the numerical methods in 2 and 3 dimensions [16-18].
They also considered mechanical properties and fluid flow in discontinuities in their latest research. The presented algorithm by Lu determines rock mass blocks geometry using vector methods in 3 dimensions [19]. In this method, planes are supposed to be limited and contact points of interface lines take planes as a vector and in the next stage, these vectors generate blocks. Ulker and Turanboy implemented genetic algorithm to determine blocks in 3 dimensions based on tree structure [20]. Jafari et al. offered a novel algorithm according to the operation on basic matrix to detect 3 dimension blocks [21], and Khishvand et al. developed this algorithm for 2 dimensions problems [22]. Table 1 summarizes researches conducted by different people in this area, in this table some other researches [23-24] as well as above mentioned works with their basis method are presented.

So far, all these investigations have been focused on the problem of finding primary blocks analytically and mathematically, but these problem applications have been neglected slightly. This paper is an effort to assess these applications and complete the previous works. As presented, all algorithms are in 2 classes of 2 and 3 dimensions. Due to unspecified features of discontinuities like length, shape and direction and uncertainty of 3D modeling of rock mass and costly operations, it's preferred to use 2 dimensions analysis.

In the previous work [25] development of the computer program was presented, the application of this program with examples will consider in this paper.

\section{MATLAB code (Computer program)}

Software and computer programs have been developed for easy and fast calculations. They can solve complex and long problems quickly. Development of computer programs is essential in any field such as rock mechanic 
and mining engineering. Due to economic and technical requirements, development of new programs and improvement of the existing ones are necessary.

Table 1. Survey of researches conducted in block detection

\begin{tabular}{|c|c|c|c|}
\hline Researcher & Date & Method Basis & Dim \\
\hline Warburton & $1983-85$ & $\begin{array}{c}\text { Geometrical } \\
\text { Parameter }\end{array}$ & $2 \& 3$ \\
\hline $\begin{array}{l}\text { Goodman \& } \\
\text { Shi }\end{array}$ & 1985 & Vector method & $2 \& 3$ \\
\hline Lin et al. & 1987 & $\begin{array}{l}\text { Topological } \\
\text { Techniques }\end{array}$ & 3 \\
\hline Heliot & 1988 & $\begin{array}{l}\text { Numerical } \\
\text { Systems }\end{array}$ & 3 \\
\hline Shi & 1988 & $\begin{array}{l}\text { Directed } \\
\text { Graphs }\end{array}$ & 2 \\
\hline $\begin{array}{l}\text { Jing \& } \\
\text { Stephansson }\end{array}$ & $\begin{array}{l}1994- \\
2007\end{array}$ & $\begin{array}{l}\text { Numerical } \\
\text { Techniques }\end{array}$ & $2 \& 3$ \\
\hline $\begin{array}{l}\text { Maerz \& } \\
\text { Germain }\end{array}$ & 1996 & $\begin{array}{l}\text { Geometrical } \\
\text { Parameter }\end{array}$ & 3 \\
\hline Lu \& Latham & 1999 & $\begin{array}{l}\text { Geometrical } \\
\text { Parameter }\end{array}$ & $2 \& 3$ \\
\hline Joaquim et al. & 2000 & Graph Theory & 2 \\
\hline $\begin{array}{l}\text { Starzec \& } \\
\text { Tsang }\end{array}$ & 2002 & $\begin{array}{l}\text { Geometrical } \\
\text { Parameter }\end{array}$ & $2 \& 3$ \\
\hline Smith & 2004 & $\begin{array}{l}\text { Geometrical } \\
\text { Parameter }\end{array}$ & $2 \& 3$ \\
\hline Lu et al. & 2002 & Vector Methods & 3 \\
\hline $\begin{array}{l}\text { Palmström_et } \\
\text { al. }\end{array}$ & $\begin{array}{l}1985, \\
‘ 01, ' 05\end{array}$ & $\begin{array}{l}\text { Geometrical } \\
\text { Parameter }\end{array}$ & $2 \& 3$ \\
\hline $\begin{array}{l}\text { Ulker \& } \\
\text { Turanboy }\end{array}$ & 2009 & $\begin{array}{c}\text { Genetic } \\
\text { Algorithm }\end{array}$ & 3 \\
\hline Zhang et al. & 2010 & $\begin{array}{l}\text { Finite Element } \\
\text { Modeling }\end{array}$ & 3 \\
\hline Jafari et al. & 2011 & $\begin{array}{c}\text { Square } \\
\text { Matrices }\end{array}$ & 3 \\
\hline $\begin{array}{l}\text { Khishvand et } \\
\text { al. }\end{array}$ & 2011 & $\begin{array}{l}\text { Square } \\
\text { Matrices }\end{array}$ & 2 \\
\hline Zhang et al. & 2012 & $\begin{array}{l}\text { Mesh Gridding } \\
\text { Technique }\end{array}$ & 3 \\
\hline
\end{tabular}

To determine block geometry in 2D, a computer program (MATLAB code) has been developed for the calculation of blocks vertices coordinates in the rock mass and the introduction of a graphical survey of rock mass face. The computer program employed in this paper is written in MATLAB ${ }^{\mathrm{TM}}$ environment.

\subsection{Computer Program Inputs}

All computer programs have one or several kinds of input data which could be graphical images, audios, videos, texts and so on. Inputs of the developed program are in text form as comes below:

\section{(1) Matrix of single discontinuities coordinate}

This matrix has 4 columns and $n$ rows, where $\mathrm{n}$ is the number of all single discontinuities. If coordinate of start and the end point of each discontinuity is shown by [Xs, Ys] and [Xe, Ye] respectively, 4 columns of each row can be expressed as [Xs, Ys, Xe, Ye].

(2) Main area

An arbitrary area forming a framework for checking discontinuities is employed. Length and width of area are manually entered as $[\mathrm{X}, \mathrm{Y}]$ format in the program.

\section{(3) Dip of joint sets}

Joint sets are also defined in the model with joint spacing and joints dip, which is the angle between $\mathrm{X}$ axis and the joints line. Numbers of joint sets are not limited in the program. For example, in order to introduce three joint sets with spacing of 5,2 and 1.5 meters and dips of 25, 90 and 150, matrixes $a=[5,2,1.5]$ for spacing and $b=[25,90,150]$ for dips should be entered manually in the program to create discontinuities network.

\subsection{Computer Program Outputs}

Outputs mean the result of processed input data by program. Outputs data can also be any kind of data such as videos, images, audios and text files. Outputs of this computer program are: 
(1) Plan of discontinuities network

The program depicts a plan of the main area and discontinuities network at the end of run. Blocks or polygons are highlighted with a different color.

(2) Coordinate of block vertices

Coordinate of each of block vertices is presented through some matrixes by the program.

\section{(3) Size of blocks}

The program saves number, size and edges coordinates of all blocks in a matrix. Size distribution diagram and other geometry characteristics of rock mass are accessible in the program.

\section{Applications}

Understanding blocks geometry is an essential issue in different domains of rock and mine engineering such as yield calculation in quarries, fragmentation energy, design of blasting pattern, block stability in slopes, block stability in underground spaces built in jointed rock masses and the prediction of dilution potential in sub-level cave mine voids. Therefore, some examples are designed to show the applications of these cases clearly.

\subsection{Quarry mines yield}

Quarries yield or the volume of appropriate blocks for Stone factories has a direct relation with the fracture system in the rock mass. Extraction direction in quarries should be selected based on fracture system in order to achieve the optimum yield. Using 2D methods, one is able to calculate the yield simply and quickly. In the following, this problem has been described via a simple example:
Specifications of an assumed bench of a quarry mine are:

- Bench dimension: 6×30 m (Height $\times$ Length)

- Joint sets properties: Joint set 1: $85^{\circ}$ dip (angle with $\mathrm{x}$ axis) and $6 \mathrm{~m}$ spacing

Joint set $2: 45^{\circ}$ dip (angle with $\mathrm{x}$ axis) and $8 \mathrm{~m}$ spacing

A schematic view of this bench face and joint sets, which are the outputs of the computer program, is shown in figure 2 .

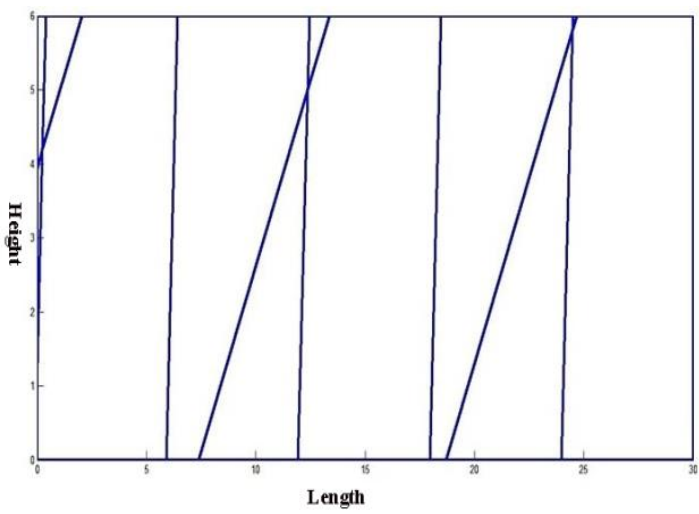

Figure 2. Face of a bench in the assumed quarry mine

Extraction of rock blocks from rock mass in quarries takes place by the creation of cutting sheets. Because of constraints in loading and handling equipment, dimensions of rock blocks should be specified. The usual dimensions of rock blocks in quarries are $3 \mathrm{~m}$ (length) $\times 2 \mathrm{~m}$ (width) $\times 1.5 \mathrm{~m}$ (height). In 2D problems, the width of rock blocks is ignored and by considering the following rules, the yield in the assumed bench could be determined:

a) Optimum dimension of rock blocks in $2 \mathrm{D}$ is $3 \mathrm{~m}$ (length) $\times 1.5 \mathrm{~m}$ (height).These blocks are called cube blocks.

b) Rock blocks smaller than $4.5 \mathrm{~m}^{2}$ and bigger than $1 \mathrm{~m}^{2}$ are shapeless blocks.

c) Rock blocks smaller than $1 \mathrm{~m}^{2}$ are waste blocks 
By considering these rules, the bench face is cut with $3 \times 1.5 \mathrm{~m}$ Vertical and horizontal cutter sheets in order to determine quarry yield in the bench. Figure 3 shows the bench face with joints and cutter sheets.

The computer program results showed that $57 \%$ of bench blocks were cube blocks, $38 \%$ were shapeless blocks and 5\% were waste blocks. These results also showed the yield of an individual bench of the mine and by calculating all benches yield, one could determine the total yield of the quarry. By using this computer program, 2D calculations become quick, simple and cheap.

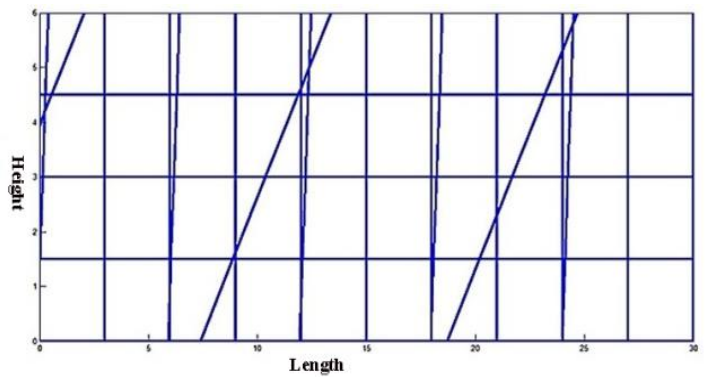

Figure 3. Mine bench face with joint sets and cutter sheets

\subsection{Fragmentation energy}

Analysis of the rock mass fragmentation by blasting mechanisms requires the perfect assessment of two main elements: geology of the site and blast design. The former includes detailed characterization of discontinuities network and rock matrix while the latter includes choosing blast parameters (pattern, energy, initiation and delays) [24]. Understanding the amount of spent energy during a blast for rock fragmentation is an essential issue, which is, in turn, related to discontinuities network and the size of rock mass blocks. Blocks size distribution is the input data to predict the required macro and micro energy in blasting and fragmentation.

An example of an iron ore mine can clarify this discussion.
An iron mine bench specifications are:

- Bench dimensions: $15 \mathrm{~m}$ (Height) and $30 \mathrm{~m}$ (Length)

- Joint sets properties: Joint set 1: $0^{\circ}$ dip (angle with $\mathrm{x}$ axis) and $1.5 \mathrm{~m}$ spacing

- Joint set 2: $20^{\circ}$ dip (angle with $\mathrm{x}$ axis) and $1 \mathrm{~m}$ spacing

- Joint set 3: $70^{\circ}$ dip (angle with $\mathrm{x}$ axis) and $1.2 \mathrm{~m}$ spacing

This bench face and joint sets are shown in figure 4 .

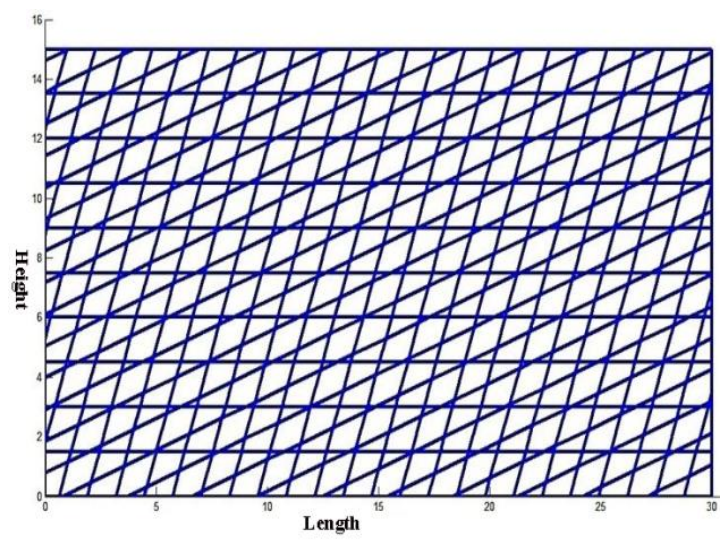

Figure 4. Iron mine bench face and its discontinuities

Block size distribution resulting from computer program is needed to determine the fragmentation energy. For the mentioned bench, block size distribution is shown in figure 5 .

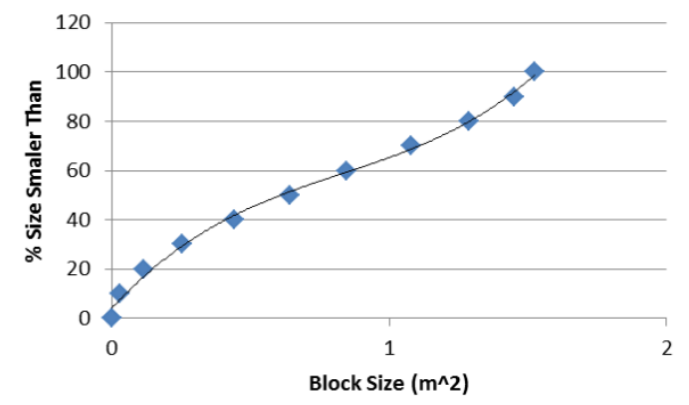

Figure 5. Block size distribution of the bench face 


\subsection{Blasting parameter}

Production of a saleable product from a mine requires a continuum series of tasks starting with blasting operation. The purpose of blasting operation is to fragment rock mass body to provide downstream processes with a suitable size distribution of rocks. The blast results (fragments size distribution, the rate of fine production, reduction in block size, induced vibrations, blast-induced micro cracks within fragments, and the shape of the muck pile) are influenced by the geometry of rock mass and blasting parameters. Using the developed computer program is suggested for designing primary blasting parameter (optimum blasting pattern and the proper use of explosives and boosters). For example, an open pit mine bench which is ready for blasting operation is shown in figure 6 . This bench has the following specifications:

- Bench dimensions: $15 \mathrm{~m}$ (Height) and $10 \mathrm{~m}$ (Width)

- Joint sets properties: Joint set 1: $0^{\circ}$ dip (angle with $\mathrm{x}$ axis) and $3 \mathrm{~m}$ spacing

- Joint set 2: $30^{\circ}$ dip (angle with $\mathrm{x}$ axis) and $3 \mathrm{~m}$ spacing

- Joint set 3: $130^{\circ}$ dip (angle with $\mathrm{x}$ axis) and $3 \mathrm{~m}$ spacing

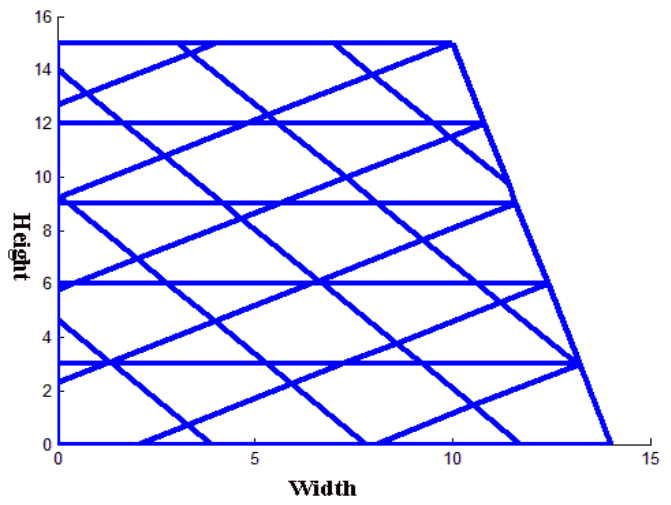

Figure 6. A ready open pit mine bench used for blasting operation
Blasting operation should have minimum drilling, minimum use of explosives and proper fragment size distribution while large rock blocks (Boulders) shouldn't appear in muckpile. According to these rules, the blasting pattern shown in figure 7 is suggested for the mentioned bench.

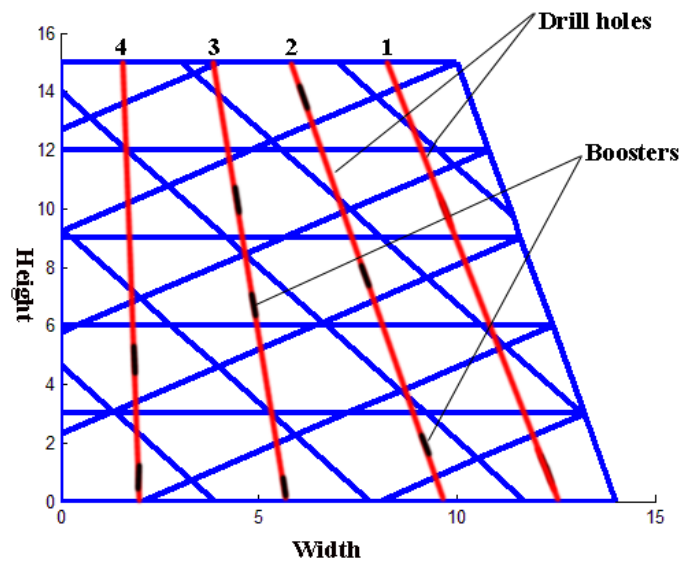

Figure 7. Suggested drill holes and the locations of boosters in the bench

Usually patterns with the same drill hole parameter are used in the mines; but, sometimes the innovative patterns are optimum. Table 2 summarizes specifications of drill holes shown in figure 7.

Table 2. Drill holes specifications in figure 7.

\begin{tabular}{cccc}
\hline $\begin{array}{c}\text { Drill } \\
\text { hole } \\
\text { NO }\end{array}$ & $\begin{array}{c}\text { Head } \\
\text { distance } \\
\text { from face } \\
\text { (m) }\end{array}$ & $\begin{array}{c}\text { Dip } \\
\text { (degree) }\end{array}$ & $\begin{array}{c}\text { Boosters } \\
\text { location } \\
\text { (distance } \\
\text { from head, m) }\end{array}$ \\
\hline 1 & 1.7 & 75 & - \\
2 & 4 & 75 & $1,8,15$ \\
3 & 5.7 & 85 & $4,9,15$ \\
4 & 8.3 & 90 & 10,14 \\
\hline
\end{tabular}

\subsection{Other applications}

There are other various applications in mining and rock mechanics. Good understanding of rock blocks conditions plays a significant role in them. 
Block stability in slopes and underground spaces is among these applications. By identifying block size, vertices and edges, one can judge stability situation and trace key blocks.

Sometimes, the stability of one or more blocks depends on the stability of an individual block. This block is called the key block. For example, block 1, which is shown in figure 8 is a key block for blocks 2 and 3 . Geometrical data of this key block is required for stability analysis and the design of supports.

It is assumed that the slope's height and face dip are $15 \mathrm{~m}$ and $75^{\circ}$, respectively. It has two joint sets with dips of $90^{\circ}$ and $130^{\circ}$ and spacing of $5 \mathrm{~m}$ and $6 \mathrm{~m}$. According to the output of the computer program, coordinates of the key block vertices could be defined as $(10,15),(13.2,2.9)$ and $(10,6.7)$. Also, the area of these blocks equals $13.4 \mathrm{~m}^{2}$. It is now possible to decide on the stability of this block through these presented geometrical parameters.

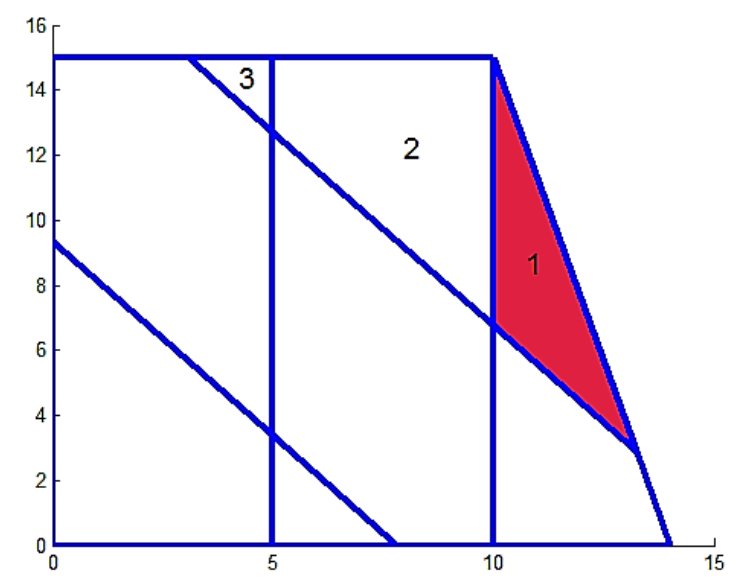

Figure 8. Geometry of a slope and a key block

Stability analysis and support designing for underground spaces also need the determination of blocks geometry. For example, as illustrated in figure 9, an underground mine tunnel collar with the height and width of $3 \mathrm{~m}$ and $4 \mathrm{~m}$ is assumed to be 10 meter below the ground surface. Some discontinuities have been surveyed above the collar as their starting and ending point coordinates are reported in table 3 .

Table 3. Specifications of the surveyed discontinuities

\begin{tabular}{ccccc}
\hline \multirow{2}{*}{$\begin{array}{c}\text { Dis- } \\
\text { continuities }\end{array}$} & \multicolumn{2}{c}{$\begin{array}{c}\text { Coordinates } \\
\text { of start point }\end{array}$} & \multicolumn{2}{c}{$\begin{array}{c}\text { Coordinates } \\
\text { of end point }\end{array}$} \\
\cline { 2 - 5 } & $\mathbf{X}_{\mathbf{s}}$ & $\mathbf{Y}_{\mathbf{s}}$ & $\mathbf{X}_{\mathbf{e}}$ & $\mathbf{Y}_{\mathbf{e}}$ \\
\cline { 2 - 5 } 1 & 5 & -10 & 6 & -5 \\
2 & 4 & -7 & 6 & -10 \\
3 & 5 & -5 & 8 & -10 \\
4 & 4 & -10 & 6 & -4 \\
\hline
\end{tabular}

It is required now to know the geometrical parameters of blocks 1, 2 and 3 for stability analysis and designing support for this tunnel.

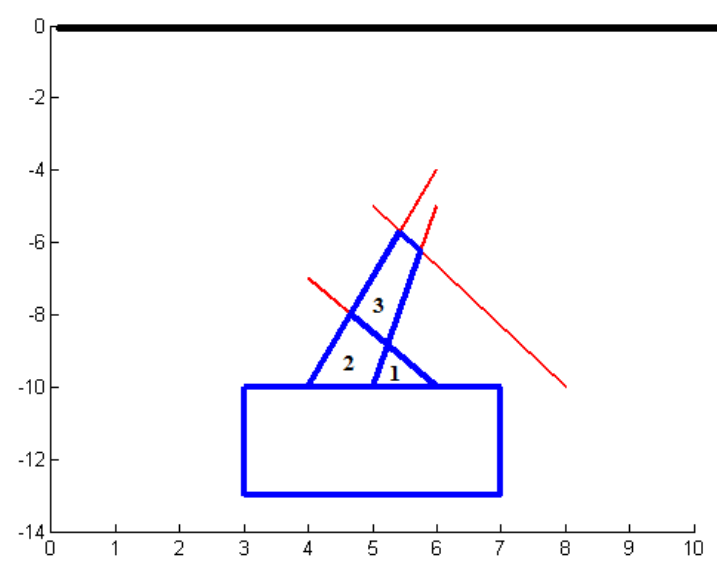

Figure 9. A mine tunnel collar 10 meters below the surface

Geometry of blocks is required for their stability analysis while coordinates of their vertices are needed for support design. Based on the computer program outputs, table 4 reports the geometrical specifications of blocks formed above the tunnel.

Ore dilution is controlled with discontinuities and structural specifications of rock mass in mines exploited with caving methods. 
Table 4. Geometrical specifications of blocks

\begin{tabular}{ccc}
\hline $\begin{array}{c}\text { Block } \\
\text { NO }\end{array}$ & $\begin{array}{c}\text { Block } \\
\text { area } \\
\left(\mathbf{m}^{2}\right)\end{array}$ & Block vertices coordinates \\
\hline 1 & 0.58 & $(6,-10)(5,-10)(5.23,-8.84)$ \\
2 & 1.42 & $(4.66,-8)(4,-10)(5,-10)$ \\
& & $(5.23,-8.84)$ \\
3 & 1.52 & $\begin{array}{c}(4.66,-8)(5.75,-6.25)(5.43,- \\
\end{array}$ \\
\end{tabular}

So another application of blocks geometry determination could be dilution assessment by caving methods of underground mining while the volume distribution and shapes of in situ blocks are required for the evaluation of ore and waste mixture during exploitation.

\section{Conclusion}

Different geological features, like tectonic activities, create fractures in rock mass and lead to discontinuities and generation of blocks. A correct understanding of these blocks' geometry is a substantial issue considered in mining and rock engineering. This paper introduced a computer program to determine the geometry of rock blocks in two dimensional spaces. This was developed by MATLAB $^{\text {TM }}$. Determination of cube blocks in quarry mines, blasting pattern calculation, optimization of fragmentation, designing support system for underground spaces and blocks stability in rock masses are all applications of blocks recognition.

\section{References}

[1] Palmström, A., Sharma, VI., Saxena, K. (2001) In-Situ Characterization of rocks: AA Balkema Publishers.

[2] Palmstrom, A. (2005) Measurements of and correlations between block size and rock quality designation (RQD). Tunnelling and Underground Space Technology, 20: 362-377.

[3] Palmstrom, A. (1985) Application of the volumetric joint count as a measure of rock massjointing. Prm.

[4] Warburton, P. (1983) Applications of a new computer model for reconstructing blocky rock geometry - Analysing single block stability and identifying keystones. 5th ISRM Congress.

[5] Warburton, P. (1985) A computer program for reconstructing blocky rock geometry and analyzing single block stability. Computers \& Geosciences. 11: 707-712.

[6] Lu, P., Latham, J-P. (1999) Developments in the assessment of in-situ block size distributions of rock masses. Rock mechanics and rock engineering. 32: 2949.

[7] Starzec, P., Tsang, C-F. (2002) Use of fracture-intersection density for predicting the volume of unstable blocks in underground openings. International Journal of Rock Mechanics and Mining Sciences. 39: 807-813.

[8] Smith, J. (2004) Determining the size and shape of blocks from linear sampling for geotechnical rock mass classification and assessment. Journal of structural geology. 26: 1317-1339.

[9] Lin, D., Fairhurst, C., Starfield, A. (1987) Geometrical identification of threedimensional rock block systems using topological techniques. International Journal of Rock Mechanics and Mining Sciences \& Geomechanics Abstracts. 24: 331-338.

[10] Jern, M. (2004) Determination of the in situ block size distribution in fractured rock, an approach for comparing in-situ rock with rock sieve analysis. Rock mechanics and rock engineering. 37: 391-401.

[11] Joaquim, AFMJF., Jorge, A. (2003) Polygon detection from a set of lines.

[12] Heliot, D. (1988) Generating a blocky rock mass. International Journal of Rock 
Mechanics and Mining Sciences \& Geomechanics Abstracts. 25: 127-38.

[13] Goodman, RE., Shi, G-h. (2013) Block Theory and its Application to Rock Engineering.

[14] Shi, G-h. (1988) Discontinuous deformation analysis: a new numerical model for the statics and dynamics of block systems: University of California, Berkeley.

[15] Maerz, N.H., Germain, P. (1996) Block size determination around underground openings using simulations. Proceedings of the FRAGBLAST 5 workshop on measurement of blast fragmentation, Montreal, Quebec, Canada, 215-223.

[16] Jing, L., Stephansson, O. (1994) Topological identification of block assemblages for jointed rock masses. International Journal of Rock Mechanics and Mining Sciences \& Geomechanics Abstracts. 31: 163-172.

[17] Jing, L. (2000) Block system construction for three-dimensional discrete element models of fractured rocks. International Journal of Rock Mechanics and Mining Sciences. 37: 645-659.

[18] Jing, L., Stephansson, O. (2007) Fundamentals of Discrete Element Methods for Rock Engineering: Theory and Applications: Theory and Applications: Elsevier.

[19] Lu, J. (2002) Systematic identification of polyhedral rock blocks with arbitrary joints and faults. Computers and Geotechnics. 29: 49-72.
[20] Ülker, E., Turanboy, A. (2009) Maximum volume cuboids for arbitrarily shaped in-situ rock blocks as determined by discontinuity analysis - A genetic algorithm approach. Computers \& Geosciences. 35: 1470-1480.

[21] Jafari, A., Khishvand, M., Rahami, H. (2011) Developing an algorithm for reconstruction blocky systems in discontinuous media: three-dimensional analysis. International Journal for Numerical and Analytical Methods in Geomechanics.

[22] Khishvand, M., Jafari, A., Rahami, H. (2011) Developing an algorithm for reconstruction of blocky systems in discontinuous media: two-dimensional analysis. Geomechanics and Geoengineering. 6: 171-183.

[23] Zhang, Y., Xiao, M., Chen, J. (2010) A new methodology for block identification and its application in a large scale underground cavern complex. Tunnelling and Underground Space Technology. 25: 168-180.

[24] Zhang, Y., Xiao, M., Ding, X., Wu, A. (2012) Improvement of methodology for block identification using mesh gridding technique. Tunnelling and Underground Space Technology. 30: 217-229.

[25] Yarahmadi, R., Bagherpour, R., Kakaie, R., Mirzaie, N.H., Yari, M.(2014) Development of 2D computer program to determine geometry of rock mass blocks. International Journal of Mining Science and Technology 24: 191-194. 